\title{
Getting the Most out of Social Media: What Is Social Media?'
}

\author{
Caroline R. Warwick, Lauri M. Baker, Jessica C. Fernandez, and Joy N. Rumble 2
}

\section{Introduction}

Over the last 15 years, social media has transformed from an up-and-coming innovation to an integral part of American communication, with seven-of-ten Americans reporting use of at least one social media platform (Pew Research Center, 2019). Social media platforms allow companies, individuals, organizations, businesses, and groups to communicate information directly with other companies, individuals, organizations, businesses, and groups. Social media has different platforms to meet different needs, including Facebook, Instagram, Twitter, YouTube, and blogging sites (Telg et al., 2018).

\section{History of Communication in Agriculture}

Until the mid-19th century, the primary source of most agricultural information was shared from farmer to farmer. As time passed, information began to be spread via radio, mail, or the still traditional face-to-face interaction. Although these forms of communication are still relevant, the internet became the primary source of information in the last portion of the 20th century and has had a significant impact on how agriculturalists receive and share information with consumers and other industry members. As such, social media platforms have paved the way for a new form of communication.
Social media has been defined by Telg and Irani as a form of new media that includes primarily internet and mobilebased tools used for sharing and discussing information using two-way communication (2012). These web-based activities usually integrate technology, telecommunications, and social interaction that allow agriculturalist and consumers alike to create and exchange information in a more interactive way then previously possible.

\section{Why Use Social Media?}

The internet has paved the way for building relationships through the exchange of information in a way that has never been experienced before. With more than 90 percent of all US consumers buying from brands they follow on social media (Williams, 2020), consumers value products that are not only convenient and healthy, but also products they associate with the individuals who have raised, picked, and packaged the food these consumers are purchasing and consuming (Hanna et al., 2011).

Social media forms the foundation for the type of interaction consumers seek to build with agriculturalists through the use of words, pictures, videos, and audio (shown in Figure 1). These forms appeal to all human senses and add value to information being shared from agriculturalists to consumers, or visa versa. In a time when transparency and authenticity is valued and desired, delivering the new

1. This document is AEC558, one of a series of the Department of Agricultural Education and Communication, UF/IFAS Extension. Original publication date August 2015. Revised July 2021. Visit the EDIS website at https://edis.ifas.ufl.edu for the currently supported version of this publication.

2. Caroline R. Warwick, science communication specialist, UF/IFAS Mid-Florida Research and Education Center, Apopka, FL; Lauri M. Baker, associate professor, Department of Agricultural Education and Communication; Jessica C. Fernandez, former graduate student; and Joy Rumble, former assistant professor, Department of Agricultural Education and Communication, UF/IFAS Center for Public Issues Education in Agriculture and Natural Resources; UF/IFAS Extension, Gainesville, FL 32611.

The Institute of Food and Agricultural Sciences (IFAS) is an Equal Opportunity Institution authorized to provide research, educational information and other services

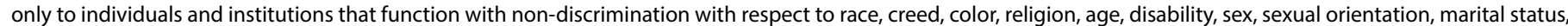

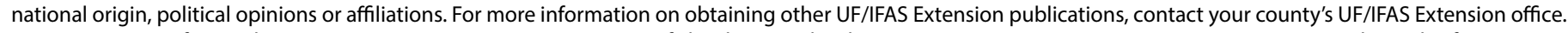
U.S. Department of Agriculture, UF/IFAS Extension Service, University of Florida, IFAS, Florida A \& M University Cooperative Extension Program, and Boards of County Commissioners Cooperating. Nick T. Place, dean for UF/IFAS Extension. 
standard of person-to-person interaction, which is achieved through social media, is crucial to the success of a business (Kaizen Digital Marketing, 2011).

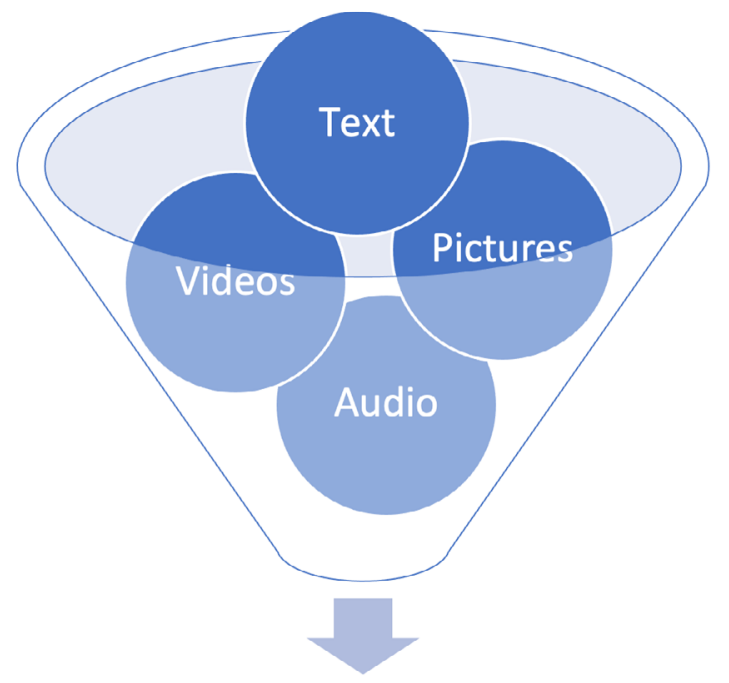

\section{Social Media}

videos, audio, and words online. This contributes to the interactive nature of such platforms.

Credits: Lauri M. Baker, Jessica C. Fernandez, and Joy N. Rumble

\section{It Is Not All about the Consumer}

Social media allows agriculturalist to be the face of products grown and harvested in the United States. With less than one percent of the American population claiming production agriculture as their occupation, and only two percent being directly involved in agricultural full time (Baker \& Irani, 2012), agriculturalists should share their story with everyone to let them know about agriculture. By adopting social media and understanding its value in today's market, agriculturalists amplify their voice. Consumers have been more willing to join in conversations with agriculturalists about controversial topics if they built trust and were transparent (Stebner et al., 2015). Social media can be an ideal way to accomplish this.

\section{Social Media Platforms}

The easiest way to get started on social media is by choosing a platform, which is a site that lets users interact with each other, upload files, and post messages, photos, and videos that visitors can see (Telg \& Irani, 2012) and that aligns with your objectives and purpose. This means the platform you choose to promote your agricultural business or share information should reach your target audience and allow you to share the information or content you would like to share. Whatever you chose, remember consistency is key. Start by signing up with one platform and then begin to integrate others slowly. As you begin to feel more comfortable with your abilities, understanding, and overall grasp on social media, you will see that if you choose to add other platforms to the mix, doing so can be easy and convenient and will allow you to reach more demographics.

The following platforms are good places to start:

- Facebook: With more than one billion active users worldwide, this social media platform will allow you to share posts consisting of words, pictures, videos, links, and more. By creating a fan page for your agricultural business, you can keep your personal profile private and still promote your commodities. You can be active on the platform by posting updates about the activities on your farm, sharing agricultural messages and images, promoting agritourism events, and seeing what other organizations or friends, individuals you share a connection with, are up to. You will also be able to see what your followers, individuals or organizations that like or stay connected with your page, are commenting on your posts and sharing with you. Facebook helps you build a relationship with your followers because both parties are involved in sharing information and actively participating in two-way communication.

- Twitter: This social media platform optimizes users' communication skills by allowing users to tweet 280 -character updates that connect them with more than 230 million active users worldwide. With concise tweets that can include quotes, links, and pictures, Twitter users can connect with other users everywhere by simply including a hashtag (\#) that allows them to search for other's tweets and to connect to other conversations about the same topic. A few examples of popular hashtags are: \#agriculture, \#UFAEC, \#AgTechUpdate, and \#FLStrawberries. Now it is time for you to get into the conversation too.

- YouTube: YouTube is a free to use and free to access video sharing website. Since 2005, YouTube has soared in popularity and utility in day-to-day life, becoming one of the most popular websites online and visitors watching around 6 billion hours of video each month. YouTube videos are free to create and free to upload, making it a favorite among organizations and individuals looking to share content.

- Instagram: Owned by Facebook and home to over a billion users worldwide, Instagram is a free platform for sharing photos and videos with other users. Instagram's video capabilities range from short-form videos, known as stories, to uploaded posts and videos, to live streaming and the production of longer videos through Instagram 
TV. Rather than focusing on words, the platform is focused on the sharing photos and videos with other users. Instagram has become a favorite among small businesses, news organizations, cultural institutions, celebrities, photographers, and musicians since it gives fans or followers unfiltered access to their video and image content.

- Pinterest, TikTok, and Blogs: As growing social media platforms, Pinterest, Instagram, and blogs focus more on sharing do-it-yourself ideas and recipes; images and videos; and online journal-style information, respectively. By linking these platforms to a Facebook or Twitter social media page, your businesses will be able to connect with more individuals across more demographics. Make sure you are actively using a social media strategy to reach your goals on these platforms.

- Others: As with any innovation, there are quite a few more social media platforms that reach different groups of people. Platforms like LinkedIn, can help you expand your professional community, while others such as YouTube can allow you to share videos of your most recent harvest and the delicious dish you prepared with it using your favorite recipe.

There is no limit to how many of these platforms you can use to create sites for your agricultural business. However, remember: quality over quantity-having one platform that you keep up with is more valuable than four platforms that are not active or up-to-date.

\section{Summary}

Social media and its many platforms are here to stay; in fact, companies and industries of all sizes now view social media as a mandatory element of their marketing strategy (Hanna et al., 2011). Now is the time to begin integrating and perfecting a social media presence for your organization or business.

For more information on getting the most out of social media, be sure to check out these other publications from faculty housed in the UF/IFAS Center for Public Issues Education in Agriculture and Natural Resources:

- Getting the Most out of Social Media: What is Social Media?

- Getting the Most out of Social Media: How to Successfully Use Social Media

- Getting the Most out of Social Media: Good Practices When Using Social Media

- Storytelling through Social Media (AEC 556)
- Story Development (AEC 553)

- Face-to-Face Storytelling (AEC 555)

- Letting Them In: Sharing Your Story with People outside of Your Industry (AEC 554)

\section{References}

Baker, L., \& Irani, T. (2012). The impact of new media on policy affecting agriculture. Journal of Applied Communications, 98(3), 17-31.

Hanna, R., Rohm, A., \& Crittenden, V. (2011). We're all connected: The power of the social media ecosystem. Business Horizons, 54, 265-273.

Kaizen Digital Marketing. (2011). Why is social media important? Retrieved from http://kaizen-marketing.com/ social-media-important/

Stebner, S., Ray, J., Becker, J., \& Baker, L. M. (2015). Totally transparent: A qualitative study about the impact of farm tours on bloggers. Journal of Applied Communications, 99(4), 48-61. https://doi.org/10.4148/1051-0834.1059

Telg, R., \& Irani, T. (2012). Agricultural communications in action: A hands-on approach (1st ed.). Clifton Park, NY: Delmar, CENGAGE Learning.

Williams, R. (2020). 90\% of people buy from brands they follow on social media, study says. Retrieved from https:// www.marketingdive.com/news/90-of-people-buy-frombrands-they-follow-on-social-media-study-says/577882/ 